\title{
Zonas tipológicas intermedias en Personas de Carlos Fuentes
}

\section{Intermediate typological zones in Persons by Carlos Fuentes}

\author{
Carmen V. Vidaurre \\ Benemérita Universidad de Guadalajara \\ vidaurrecarmenv@gmail.com \\ https://orcid.org/0000-0001-8390-5937
}

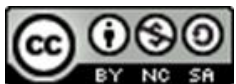

(c) UNAN-Managua

Recibido: julio 2019. Aceptado: enero 2020

DOI https://doi.org/ DOI https://doi.org/10.5377/rll.v6i1.10127

\section{RESUMEN}

Aproximación analítica al libro Personas de Carlos Fuentes, publicado póstumamente, en el que se reúnen fragmentos de memorias y semblanzas sobre un conjunto de notables personajes entre los que se encuentran Alfonso Reyes, Luis Buñuel, François Mitterrand, André Malraux, Pablo Neruda, Julio Cortázar, Fernando Benítez, Susan Sontag, Lázaro Cárdenas.

Esta obra hace evidente la presencia de elementos propios de distintos géneros (testimonio, biografía, memoria, ensayo.), punto en el que se centra este estudio, desde un enfoque metodológico-analítico, para precisar las consecuencias que la recuperación de estos modelos retóricos tienen, desde el punto de vista ideológico y de los procesos de comunicación

Palabras clave: Literatura Mexicana, Tipología textual (géneros), Análisis Literario.

\begin{abstract}
Study of the Book of Carlos Fuentes, published posthumously, in which fragments of memory and sketches on a remarkable set of characters to include Alfonso Reyes, Luis Buñuel, François Mitterrand, Andre Malraux, Pablo Neruda, Julio Cortázar, Fernando Benítez, Susan Sontag, Lázaro Cárdenas.

This work makes evident the presence of elements of different genres (testimony, memory, biography, literary essay) point at which this study focuses, from a methodological and analytical approach to point out the consequences that the recovery of these rhetorical models they have, from the ideological point of view and communication processes.
\end{abstract}

Keywords: American Literature, Text typology (genre), literary analysis.

La transgresión a las normas de género y el sincretismo se manifiestan de variadas formas en los escritos de Carlos Fuentes, en los que la reescritura de la historia, el mito y la ficción se entremezclan constantemente. 
Personas del escritor mexicano, obra póstuma, publicada en 2012, es un conjunto de doce textos breves que han sido calificados como «semblanzas»; sin embargo, una lectura analítica pone en evidencia la presencia de propiedades discursivas del testimonio, la biografía, la memoria, la ficción narrativa y el ensayo, en esos escritos. Aquí, nos proponemos hacer visibles tales fenómenos, a partir de algunas aportaciones teóricas formuladas sobre los géneros y sus redefiniciones en el siglo XX. Para esto, primeramente, retomamos las afirmaciones expresadas por Tzvetan Todorov en «El origen de los géneros» (Todorov 1988, pp.31-48), quien define los géneros como codificaciones de propiedades discursivas específicas que se hacen manifiestas en las obras (es decir, definidos de un modo descriptivo y no normativo, y por ello distinto al de las antiguas preceptivas y retóricas), al mismo tiempo que confronta algunas consideraciones expuestas por Maurice Blanchot sobre la no vigencia de los conceptos genéricos.

En su trabajo, Todorov destaca que la transgresión al género no invalida su existencia, con estas palabras:

Que la obra "desobedezca" a su género no lo vuelve inexistente [...] En principio, porque la transgresión para existir, necesita una ley [...] Pero hay más [...] apenas admitida en su estatuto excepcional, la obra se convierte, a su vez [...] en una regla [...] No ha habido nunca literatura sin géneros [...] y la cuestión de los orígenes no puede abandonar, históricamente, el terreno de los propios géneros (Todorov 1988, pp.33 y 34)

Las diferencias tipológicas entre literatura e historia se han transformado con el tiempo. En el contexto contemporáneo - y aunque en textos específicos tales diferencias se presenten como zonas o fronteras «diluidas» -, una de las propiedades discursivas de los géneros históricos la constituye el tipo de fuentes documentales y el tratamiento que a éstas se les da, pues sabemos que existen corpus legitimados o reconocidos como fuentes de la historia, al margen del grado de subjetividad manifiesta en sus enunciados y de las mediaciones ideológicas que hagan visibles. De tal suerte que la cita literal del documento legitimado o reconocido como fuente, constituye una de las propiedades discursivas de la historia; aunque tal rasgo por sí mismo no sea suficiente para hablar de género histórico (en sentido estricto) y haya tipos textuales que no involucren dicha propiedad, sino excepcionalmente, 
como el testimonio (considerado una de las fuentes de la historia; aunque, como disciplina científica, la historia le dé, en cierto momento, mayor peso a otro tipo de fuentes ${ }^{1}$ ).

El escrito narrativo literario, por su parte, ha sido caracterizado como un tipo textual en el que el dato y la fuente histórica son tratados con "libertad", recreados, ficcionados, resemantizados. A tal punto que sólo en la medida en que el texto de ficción se aproxima a la literalidad del documento histórico y del dato histórico, puede decirse que participa de aquél.

Es en este sentido, aunque también en otros, que las «zonas intermedias» entre la historia y la ficción se hacen presentes en muchos escritos de Fuentes. En Terra nostra (Fuentes, 1976a), por ejemplo, el narrador recurre a la cita y recreación de abundantes fuentes históricas ${ }^{2}$ y se complementa tales citas (sin comillas), y variantes de las mismas, con la información que brinda en su ensayo Cervantes o la crítica de la lectura (Fuentes 1976b)3. Otro ejemplo nos lo ofrece Adán en Edén (Fuentes, 2009), narración del mismo Fuentes que ha sido caracterizada, por su propio autor, como una "novela periodística" ${ }^{4}$, pues diversas anécdotas referidas en el libro derivan de notas de diarios, y la retórica de la nota informativa se hace presente en algunas partes de la narración; aunque también, en esta novela se recrean diversos materiales míticos de origen diverso, y estos materiales se funden con elementos intertextuales literarios: el epígrafe de la novela nos refiere al Paraíso perdido de John Milton y la narración constituye una variante de una obra humorística de Mark Twain, Extracts from Adam's Diary de 1904, aparecen personajes que figuraban ya en otros libros de Fuentes, como Jenaro Ruvalcaba, de La voluntad y la fortuna (Fuentes, 2008), descrito ahora como un "penalista de escaso

\footnotetext{
${ }^{1}$ Sabemos que se consideró al testimonio como una fuente primaria del conocimiento de la historia. Sin embargo, el carácter fragmentario y distorsionado de la perspectiva del individuo fueron argumento para que este tipo de declaración se cuestionara y se señalara la necesidad de la intervención del historiador con el fin de homogeneizar el tipo de información brindada por el testimonio. Su "dudosa fiabilidad" llevó a que se prefiriera prescindir de su uso o que, en caso de recurrir a él, fuera apoyando a otras fuentes de conocimiento más fiables. En los últimos años se ha modificado esta concepción, tanto debido a la aparición de nuevos ámbitos de investigación histórica, como por el problema de representar ciertos hechos: el holocausto, las represiones dictatoriales en Latinoamérica, las violaciones a los derechos civiles en las dictaduras, etc. -para referirnos sólo a ejemplos del siglo XX, pues si aludiera a casos del pasado esta nota se alargaría notablemente-. Aclaramos también que al hablar de «nuevos ámbitos de investigación histórica», se hace referencia al auge de la historia oral y a la incidencia que tuvieron los diversos estudios acerca de la memoria colectiva y de las representaciones sociales, así como a la historia de las mentalidades, líneas de investigación desarrolladas desde hace ya varias décadas (es decir, no tan "nuevas").

2 Entre los abundantes documentos históricos que son intertextos citados o «recreados» en la novela se encuentran: el Diario de navegación de Colón, en la versión que Bartolomé de las Casas "traduce" al castellano, las Cartas de relación de Hernán Cortés, la Historia verdadera de la conquista de Nueva España de Bernal Díaz del Castillo, Las cosas de Nueva España de Bernardino de Sahagún, La visión de los vencidos de Ángel María Garibay, etc. (Para un estudio detallado se puede consultar: Vidaurre 2004: 53 y ss.).

${ }^{3}$ Sobre la identificación y el estudio de las fuentes históricas en Terra nostra y Cervantes o la crítica de la lectura se puede consultar, entre otras obras el trabajo de José Miguel Oviedo sobre Terra nostra, el de Santiago Juan Navarro, el de Zunilda Gertel.

${ }^{4}$ Escrita por un "lector de periódicos, y las noticias tienen que ver con ajusticiamientos, violencia, crimen organizado y capos de la droga". Carlos Fuentes, citado por: Daniel Alberto Bedolla (2011:1).
}

Carmen V. Vidaurre Zonas tipológicas intermedias......pp. 12 28 
renombre". También reencontraremos a Rodrigo Pola, personaje de La región más transparente (Fuentes, 1958), convertido en un anciano zar de las comunicaciones. Encontramos también personajes "reales", participando en alguna anécdota que no excluye la ironía y el juego: Carlos Monsiváis, Sergio Ramírez, Tomás Eloy Martínez, una ancianita que dice llamarse Sara García, etc.

Recordaremos que la inclusión de personajes históricos, al lado de otros de ficción o de estirpe mítica, figuran en otras obras de Fuentes, como La región más transparente (Fuentes, 1958), pero también La silla del águila (Fuentes, 2003) en la que se nos relata un futuro hipotético en el que el PRI ha regresado al poder presidencial, y en cuyos personajes podemos identificar figuras históricas del pasado, o más bien de pasados heterogéneos, como: Séneca, Tácito, Calígula, César Augusto, Ruiz Cortines, Adolfo López Mateos, Miguel Alemán, Ernesto Zedillo, etc.; pero estos personajes están conformados a partir de la fusión de elementos históricos y de otros elementos meramente ficticios. Hay también referencias a otros personajes que sólo se alteran muy parcialmente o no se modifican, como: Federico Reyes Heroles, Lázaro Cárdenas del Río, Fidel Castro, Guillermina Guillén, Jefa de Prensa en PRD Nacional, transformada en la narración en la Secretaría del Medio Ambiente, José Luis Cuevas, Juan Goytisolo, Susan Sontag, el Comandante Marcos, convertido en marca y motivo de recuerdos turísticos revolucionarios; también encontramos al escritor, periodista y cineasta, Armando Ayala Anguiano, y al doctor en filosofía que fue asesor de Andrés Manuel López Obrador, José María Pérez Gay. Otros de los personajes derivan de textos literarios, como Olegario Santana, que proviene de la novela Santa María de las flores negras (2002) del escritor chileno Hernán Rivera Letelier (recurso que Fuentes empleó en otras de sus obras, ejemplo significativo de ello es Terra nostra). Las referencias intertextuales nos remiten igualmente a anécdotas y textos históricos, y otros literarios, como los Comentarios sobre la guerra de las Galias de Julio César, la Germania de Tácito, el Tratado de Guerra de Carl von Clausewitz, la Historia de Roma de Tito Livio, Las cuitas del joven Werther de Goethe, así como a otros textos a los que se rinde homenaje (Noticias del Imperio, Le vicomte de Bragelonne, la «Suave Patria», La novelas ejemplares de Cervantes, la autobiografía de Luis Buñuel, y obras del renacimiento italiano como la Divina Comedia y El príncipe de Maquiavelo, etc.) ${ }^{5}$.

En Personas hay un «Preámbulo» que es en realidad un breve texto sobre el periodista nacido en Argelia, Jean Daniel Bensaïd, escrito que participa de elementos propios de la semblanza histórica, en la medida en que se señalan datos registrados en documentos periodísticos y autobiográficos ${ }^{6}$, pero

\footnotetext{
${ }^{5}$ Para un estudio detallado de estos y otros materiales intertextuales presentes en las obras narrativas de Carlos Fuentes remitimos al lector a otros de nuestros estudios señalados en la bibliografía.

${ }^{6}$ La amistad del personaje con Albert Camus, sus viajes a Washington y La Habana, su entrevista con John F. Kennedy, sus labores periodísticas, etc. Remitimos al lector a las obras de Jean Daniel Bensaïd señaladas en la bibliografía.
} 
también hay datos ficcionales, apreciaciones subjetivas, generalizaciones, focalizaciones en el personaje que corresponderían a la perspectiva de un narrador omnipresente que conoce incluso las intenciones y sensaciones de los personajes, su interioridad y pensamientos:

Era joven (para un francés). Bien parecido (para su edad). Inteligente (como casi todos los franceses). Y era misterioso. Tenía un aire de personaje de Graham Greene o de Eric Ambler [...] Lo mueve una sensación hiriente: la cruel intimidad, no de Kennedy y Castro, sino de Estados Unidos y Cuba... (Fuentes 2012, pp. 9 y 10)

El escrito también participa del testimonio y la biografía, cuando el narrador asume la primera persona del singular, característica del escrito testimonial:

... del hombre que conocí en México, el que venía de Washington e iba a La Habana. Creí entenderlo un poco mejor durante la visita a México del presidente François Mitterrand en 1981. Simpatizante del presidente, simpatizante del socialismo... (Fuentes, 2012, p. 10)

O cuando el narrador se presenta como el del testigo veraz de los hechos, y asume el «yo» autobiográfico, de quien es protagonista de su propia historia y la refiere en una visión retrospectiva:

... me reservaban un ejemplar de L'Express primero, del Observateur enseguida [...] Era nuestra manera de ligarnos al mundo, fuera de las exigencias del nacionalismo mexicano. Nuestra manera, leyendo a Jean Daniel, de hacernos parte del mundo, partícipes de sus peligros y oportunidades también [...] de entendernos mejor a nosotros mismos. (Fuentes, 2012, p. 12)

En el apartado titulado «Alfonso Reyes», por ejemplo, el «yo» testimonial no es el del autor del libro, sino el del propio Reyes, pues el narrador adopta el estilo directo y es Alfonso Reyes quien expresa: «Yo no he vuelto a ser feliz desde aquel día» (Fuentes, 2012, p. 13). Posteriormente, el relato es referido en tercera persona y es el narrador quien refiere el acontecimiento histórico y habla de Alfonso Reyes en tercera persona, ficcionalizado al padre de Reyes, mediante el comentario final añadido al acontecimiento histórico: «... murió acribillado el general Bernardo Reyes, padre de mi amigo don Alfonso. Una larga bala lo mató. Venía persiguiéndolo toda la vida...» (Fuentes, 2012, p. 13). Cambios que hacen evidente la construcción de una instancia enunciativa compleja en el escrito, y permiten identificar la presencia de diversas voces que se mimetizan en una, la de la narración asumida por Carlos Fuentes, que se asume como sí mismo. 
Constantemente, los datos históricos se intercalan con apreciaciones subjetivas y comentarios personales que caracterizan a los personajes y los hechos, y que implican una concepción particular de la historia:

... el golpe se quedó en el hijo, vivo siempre, en algún repliegue del alma [...] El asesino de Madero, Victoriano Huerta, se transforma -como Pinochet en otro acto trágico, tras la muerte de Salvador Allende... (Fuentes, 2012, p.15)

Posteriormente, las apreciaciones dan pie a la semblanza de Bernardo Reyes que se enlaza con el «testimonio» de propio Alfonso Reyes, proporcionado a partir de una cita textual de un escrito del destacado intelectual, la «Oración del 9 de febrero»: "Junto a él no deseaba más que estar a su lado...» (Reyes, 1985, p. 25).

Más adelante, el narrador se focaliza en el personaje de Alfonso Reyes y busca ofrecer la visión subjetiva de Reyes, entremezclando apreciaciones, frases textuales dichas o escritas y referencias a hechos históricos -algunos de los cuales son comentados por el narrador de este libro-, pasando de la historia individual a la historia colectiva, al abordar diversos acontecimientos ${ }^{7}$, en transiciones que van de la semblanza, a la narración, de la cita a la caracterización ideológica, y empleando registros propios del ensayo de estética literaria ${ }^{8}$ o prometiendo contar en otra parte su relación personal con Alfonso Reyes, antes de citar fragmentos de una carta que aquél enviara al padre de Carlos Fuentes, para crear un collage verbal o un pastiche que participa de registros de la carta citada, el ensayo, el testimonio, la historia colectiva, etc.

El apartado titulado Luis Buñuel inicia con una confidencia relatada por un narrador que asume el yo de la autobiografía ${ }^{9}$, su narración se salpica con frases que dan testimonio sobre Buñuel, que esta vez no refieren a la cita textual de un escrito sino a la información proporcionada por el testigo y coprotagonista del relato: el propio Fuentes. También se observa que diversos párrafos derivan al ensayo cinematográfico, al ensayo artístico. En ocasiones, el narrador reduce a un discurso contado las palabras del personaje, y habla por él, en lugar de él, al recontar lo que aquél le había contado. El dato comprobable y el imposible de comprobar se entremezclan, para ofrecer una semblanza cuyos

\footnotetext{
${ }^{7}$ La expulsión del pueblo yaqui, las propuestas del Ateneo, el pueblo brasileño, los intelectuales argentinos, etc.

8 «Para Reyes la literatura no es estado de alma que conduce a la santidad o al melodrama. Es palabra trascendida, es lenguaje dentro del lenguaje. La literatura narra un suceder imaginario que no se corresponde necesariamente con lo real, pero que constituye lo rea -añade a lo real algo que antes no estaba allí». (Fuentes 2012: 22]).

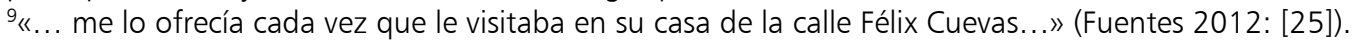


niveles de ficcionalidad se hacen palpables en las comparaciones que el narrador emplea («Buñuel sonríe como el gato de Alicia, resistiéndose a desaparecer.... ${ }^{10}$ ).

En otros apartados, el «nosotros» testimonial que se asume se suma a estrategias en las que las palabras de José Campillo se continúan en las palabras de Alfonso Reyes, derivan hacia el testimonio en tercera persona sobre Jorge Portilla, Raúl Medina Mora, o nos ofrecen un retrato muy distinto al que hace la pintora Remedios Varo del doctor Ignacio Chávez. En ocasiones ese «nosotros» que se asume es el del testigo colectivo (al hablar de Mitterrand, de Malraux), aunque eventualmente se vuelve un «yo» coprotagonista o un «yo» observador (cuando habla de Fernando Benítez, Julio Cortázar, Pablo Neruda).

El narrador se precisa, repetidas veces, como sujeto colectivo que describe los valores, ideología y experiencia del grupo con el que se identifica, y señala las modalidades de pertenencia a ese grupo, la forma en que el sujeto individual representa al grupo; o se separa de él. La identidad individual y la colectiva se confunden, entre los registros propios del ensayo sobre filosofía del derecho. Lo general define lo particular, entremezclándose con registros del discurso frecuente en el análisis político y económico (al hablar de John Kenneth, por ejemplo).

En otras partes, el narrador habla por el otro y favor del otro (al tratar sobre Edith Stein, Anna Ajmátova), llega a transcribir el «nosotros» del sujeto femenino, con el que también se identifica culturalmente, espacialmente, o por un oficio compartido (por ejemplo, al referirse a Susan Sontag y María Zambrano).

Los cambios de registros y de tonos resultan casi imperceptibles y no disminuyen el efecto de unidad, pero su presencia en el texto resulta significativa y permite identificar la forma en que funciona el libro, pero para establecer esto tendremos que considerar ahora varios puntos referentes a los tipos textuales (géneros) de los que participa la obra.

Renato Prada Oropeza, en su estudio sobre el discurso testimonial, señala un punto que tendremos que rescatar aquí:

... estamos caracterizando un tipo de discurso: por ello, estamos obligados a tomar en cuenta la intencionalidad del sistema verbal que se manifiesta en el discurso, así como la función de sus elementos pragmáticos en relación con las convenciones sociales que instauran el discurso

10 (Fuentes 2012: 44). 
de una práctica significante dentro de los marcos de un circuito de comunicación concreto (Prada Oropeza 2001, p. 14)

Estas observaciones resultan sumamente importantes cuando consideramos que la semblanza, histórica o literaria, introduce o presenta un personaje al receptor potencial de la misma, y ofrece elementos, aunque esquemáticos, que se consideran representativos de dicho personaje. Constituye un tipo textual afín a la biografía y como ella apela a la construcción y preservación de una memoria sobre determinadas acciones individuales. Se suele distinguir del testimonio en el nivel de la enunciación, porque éste, no habla de una tercera persona que es presentada a otros. En cambio, del testimonio, John Beverley señala:

... es una narración [...] contada en primera persona gramatical por un narrador que es a la vez el protagonista (o el testigo) de su propio relato. Su unidad narrativa suele ser una "vida" - una vivencia particularmente significativa (situación laboral, militancia política, encarcelamiento, etc.). La situación del narrador en el testimonio siempre involucra cierta urgencia o necesidad de comunicación que surge de una experiencia vivencial de represión, pobreza, explotación, marginalización, crimen, lucha. En la frase de René Jara, el testimonio es una narración de urgencia que nace de esos espacios donde las estructuras de normalidad social comienzan a desmoronarse... (Beverley, 1987, p. 157)

Semblanza y testimonio constituyen, a partir de lo aquí citado, dos tipos textuales no sólo diferenciados por sus características formales, también por las funciones e intencionalidades manifiestas en cada uno de ellos. Sin embargo, el texto de Fuentes nos enfrenta a un discurso que lo mismo participa de características y funciones de la semblanza y del testimonio, por lo que debemos profundizar un poco más en este aspecto.

John Beverley señala claramente la distinción enunciativa que caracteriza el testimonio, en tanto narración en primera persona, realizada por un narrador que a la vez el protagonista y/o el testigo de su relato. Destaca también algunos elementos recurrentes en el sistema de comunicación implicado en el testimonio (la necesidad de su comunicación) y del contexto en que se suele producir (un espacio donde la «normalidad social» comienza a desmoronarse). Estos puntos resultan también significativos al aplicarlos al escrito de Fuentes, en la medida en que los registros del testimonio nos estarían informando, indirectamente, de la percepción del productor del escrito sobre el contexto social en el que se está produciendo el mismo: un contexto en el que quien produce el discurso percibe cierta urgencia o necesidad de expresarse, derivada de experiencias vivenciales que involucran 
«marginación» o «conflicto», resquebrajamiento de una «estabilidad», aspectos que tendremos también que precisar más adelante, en el caso del libro de Fuentes.

Por su parte, Renato Prada Oropeza añade a lo anteriormente observado sobre el testimonio, lo siguiente:

...todo discurso testimonial es siempre explícitamente referencial y pretende un valor de verdad [...] esta intencionalidad lo motiva en cuanto discurso. Además, el discurso testimonial, es siempre intertextual pues, explícita o implícitamente, supone otra versión o interpretación [...] sobre su objeto (referente), una versión opuesta, contraria o distorsionada, a la cual corrige, se opone o rectifica. (Prada Oropeza, 2001, p. 11).

La pretensión de verdad del testimonio y su definición como "otra versión", de una versión previa que funciona como material intertextual, son rasgos también importantes de este género que busca corregir o rectificar una versión previa de su actuar y del actuar de otros. Pero, además, debemos considerar que las caracterizaciones que ofrecen los dos teóricos que hemos citado sobre el testimonio están condicionadas, incluso determinadas, por el origen mismo del testimonio como tipo discursivo y textual, pues no podemos ignorar que el testimonio surge en el llamado discurso forense y más específicamente en el seno del discurso judicial-procesal, en el que se solicita a una «asamblea» determinadas demandas ${ }^{11}$. Es del ámbito jurídico que el testimonio pasa a la poesía dramática, para expresar desde el «yo testimonial», una «verdad» que lleva implícitas una serie de argumentaciones, ante una situación que involucra un acto de impartición de justicia moral y ética (aunque ya no legal, pues el testimonio que se expresa en el ámbito de la literatura, «queda» fuera del contexto del contexto del proceso judicial-procesal, pero no del «juicio público»). Son éstas las propiedades discursivas específicas del género testimonio desde su origen y esto punto no puede ser ignorado aquí, particularmente si consideramos que el autor de la obra que es objeto de nuestro estudio poseía una competencia profesional específica de dominio sobre el discurso jurídico-legal ${ }^{12}$.

Otros rasgos señalados sobre el testimonio, por los autores que hemos citado antes, corresponden a características particulares de ciertos textos, más que a propiedades discursivas del género testimonial en su conjunto, por lo que no los consideramos aquí. Como tampoco consideramos algunos rasgos

\footnotetext{
11 Sobre estos puntos específicos del papel del testimonio dentro del contexto de su origen se pueden consultar la Retórica de Aristóteles y la obra de Roland Barthes, La aventura semiológica, incluidas en la bibliografía del presente trabajo.

12 Cursó la carrera de Derecho en la Universidad Autónoma de México, posteriormente cursó estudios de posgrado en el Instituto de Altos Estudios Internacionales y de Desarrollo (IHEID), en Ginebra, ejerció en ámbito diplomático y participó constantemente con profesionales del ámbito profesional.
} 
que, desde la perspectiva teórica de Prada Oropeza, sirven para distinguir entre testimonio y biografía o memorias, aclarando que, lo que nos hace diferir de algunas de sus afirmaciones, es que considera que el «yo» testimonial expresa un dispositivo lingüístico que puede ser asumido por cualquiera; mientras que la autobiografía y las memorias son para él géneros que manifiestan una postura individualista, propias de un narrador coherente y dueño de sí mismo que se apropia de la palabra para manifestar su singularidad, experiencia y estilo. Aceptar esto equivaldría, no sólo aceptar que las memorias y la autobiografía constituyen tipos textuales que sólo son practicadas por sujetos que son «dueños de sí mismos» y capaces de expresar su singularidad, significaría también aceptar que el «yo» testimonial no puede ser un sujeto narrador coherente, dueño de sí mismo, capaz de expresar en el «yo» su singularidad, su experiencia e incluso su «estilo». Puntos que por supuesto rechazamos.

Además, en el testimonio, no se borra la función del autor, aunque Renato Prada lo afirme, la reivindicación del yo testimonial no siempre se basa o fundamenta en la fama o prestigio de quien escribe, aunque puede basarse parcialmente en ello, su «autoridad» deriva justamente y de manera principal en la pretensión de participación directa de la experiencia que se relata y por ello, el testimonio no queda libre de una instauración de jerarquía frente a otros «poderes», clases o estamentos. La expresión de una identidad colectiva puede hacerse manifiesta tanto en el testimonio como en la memoria, e incluso en la autobiografía, por lo que tampoco podemos considerarla como un rasgo tipológico definitorio del testimonio. No es tampoco la veracidad del testimonio lo que lo define como tal, es su pretensión de verdad y la demanda de ser conocido ante una situación que implica impartición de justicia (individual o colectiva), de tipo moral (cuando se produce fuera del ámbito jurídico) o legal (cuando se produce en el seno de aquél).

Autobiografía, memoria y testimonio enfatizan el «yo» que relata, de una manera análoga, en tanto el enunciador se instaura como figura de «autoridad», al ser protagonista y testigo de lo que refiere; pero, mientras en la autobiografía, el objetivo principal del relato es el dejar memoria de la experiencia vital del sujeto enunciador, como ocurre también en la memoria (aunque ésta lo haga de manera retrospectiva siempre, en tanto en la primera, pueda mezclarse o incluirse una visión retrospectiva y otra centrada en el presente); en el testimonio el objetivo es otro: es el de argumentar dicha experiencia vital de la que se ha sido participe como protagonista o testigo, como defensa hacia sí, o acusación hacia otro(s), porque se busca la impartición de una justicia moral o legal, que se percibe como no satisfecha, no otorgada, en un contexto que, quien da el testimonio, considera apremiante. 
Estas funciones son recuperadas en el escrito que estudiamos, al lado de las funciones que cumplen las semblanzas como presentaciones de figuras o personalidades que se busca caracterizar de modo positivo, para que sean valoradas por sus aportaciones y singularidades, destacando también el valor de su identidad. Lo que se manifiesta como particularmente significativo cuando tomamos en cuenta la relación que en el escrito se establece entre el narrador y tales personalidades.

Respecto al ensayo como género o tipo textual específico que también deja huellas en el libro de Fuentes, tendremos que considerar otros puntos.

Belén Hernández, en el «Prefacio» a la obra de la que es editora junto con Vicente Cervera y María Dolores Adsuar, titulada El ensayo como género literario, señalaba dos fenómenos que confluyen en el ensayo:

... por una parte la expresión de la subjetividad del autor, consciente de la capacidad estética de su obra, la divagación del escritor que se presenta a sí mismo como tema y argumento [...], herencia de Montaigne; y por otra el deseo de dar respuesta a las demandas concretas del lector moderno, de un receptor que requiere un estímulo intelectual y estético condensado en pocas páginas y accesible a sus posibilidades culturales. (Cervera, Hernández y Adsuar , 2005, p. 8)

Con estas palabras, Belén Hernández destaca dos puntos que desde su perspectiva caracterizan la variable configuración del ensayo literario, reconocido por ella misma como un tipo de texto, no sólo sumamente debatido sino también, difícil de definir. De la obra de Montaigne, Jesús Navarro Reyes ha señalado lo siguiente:

Los Ensayos de Michel de Montaigne irrumpen a finales del Renacimiento presentándose como una obra absolutamente novedosa y original, única en su especie [...] manteniendo una actitud puramente escéptica, no aspiran a tener por objeto nada ajeno, nada que esté más allá de su alcance y que no sea posible conocer de modo directo [...] Por ello versan [...] acerca de lo propio, de su propio autor, como él mismo nos indica desde el prólogo [...] (Navarro Reyes, 2003, p. 271).

Ese énfasis en el tema de la propia identidad en la obra de Montaigne ha sido destacado por muchos de los estudiosos del trabajo del pensador francés, pues no sólo es un rasgo importante, ofrece modalidades particulares: «Habría en los Essais un yo que hablaría constantemente de sí, pero que no sabría muy bien dónde se encuentra ni qué es él mismo [...] la autoconciencia iría tratando de realizarse» (Raga Rosaleny 2010: 26); «En 1580 Michel de Montaigne presentó "al lector" un proyecto Carmen V. Vidaurre Zonas tipológicas intermedias......pp. 12 28 22 
literario [...]: una colección de textos [...] que tenían como tema el retrato de sí mismo» (Trías, 2003, p. 47); el mismo Jesús Navarro Reyes resumirá el propósito de su trabajo con estas palabras:

Es preciso practicar una cierta arqueología para encontrar, tras el texto de los Ensayos, los vestigios de un poderoso esfuerzo: aquél que realizó su autor para transformar los textos de otros en lenguaje acerca de sí. La obra de Montaigne surge así a partir de lo ajeno, atraviesa los caminos del yo, y vuelve a encontrar al otro en la figura del lector (Navarro Reyes, 2003, p. 271).

Los escritos de Michel de Montaigne serán caracterizados como textos en los que, aunque el tema principal es el de la identidad de quien se expresa, dicha identidad es puesta en crisis, no sólo porque no se concibe como una "esencia", también porque se construye a partir de lo que otros perciben y expresan sobre diversos aspectos de la realidad de la forma parte quien se expresa en los escritos.

Debemos considerar que, desde la perspectiva de los estudios tipológicos contemporáneos de los textos, los «tipos de escritos» no son considerados desde un enfoque normativo (aunque para algunos estudiosos los viejos esquemas de las jerarquías se conserven) y se tiene consciencia que las «matrices tradicionales» O «modelos» primeros se ven afectadas por diversos cambios en su desarrollo histórico. Sin embargo, el «modelo» de Montaigne resulta importante, aunque no es el único, al estudiar Personas de Carlos Fuentes, en la medida en que su autor también se centra en la descripción de una identidad, y también transforma los textos de otros (citas, alusiones, recreaciones) en lenguaje acerca de sí, y en tanto que igualmente considera «lo ajeno» y encuentra al otro como parte de sí, ya se trate de personajes e intelectuales a quienes conoció, de la figura del lector, o de otras generaciones distintas a la suya; pero igualmente, en la obra de Fuentes, encontramos separaciones del «modelo» primero, pues no se reflexiona sobre una identidad que sólo se identifique con él «yo», se trata de una identidad colectiva de un «nosotros», de un sujeto colectivo, del que se habla y por el que se habla, tanto en singular como en plural, como lo demuestra la siguiente cita:

Pepe Campillo era amigo muy cercano del trágico, vibrante y socrático Jorge Portilla, el más brillante filósofo mexicano de su generación, un católico apadrinado por Nietzsche y Dostoyevsky. Con él, con Campillo, con Raúl Medina Mora, algunos miembros de mi generación descubrimos la realidad de la cultura cristiana en México [...], la civilización católica aparecía en las discusiones del grupo de Campillo como una construcción racional estremecida por la sospecha trágica. Sentí entonces que, acaso, sólo el catolicismo nos ofrece a los latinoamericanos la posibilidad de ese conflicto entre valores... (Fuentes, 2012, p. 48). 
El procedimiento empleado en la cita se reitera a lo largo del escrito de Fuentes, en ocasiones procediendo de modo distinto, iniciando por hablar del sujeto colectivo con el que identifica, para luego hablar de otros, o partiendo del «yo» individual para reflexionar sobre la identidad cultural, ideológica, moral, de «otros» y de sí mismo. El autor no sólo habla a nombre del grupo y de sí, también deja que otros hablen de ese sujeto colectivo del que forma parte, y deja que otros hablen por él, asiendo suyas las palabras que otros han expresado sobre quienes considera contribuyeron a la configuración de su propia identidad:

Como escritor joven, yo tuve la suerte de contar con [...] influencias mayores en mi formación. En primer término la de Alfonso Reyes, miembro fundador de El Colegio Nacional, a quien Jorge Luis Borges llamó, con toda razón, el mejor prosista de la lengua castellana del siglo pasado. Don Alfonso [...] me dispensó [...] atención y enseñanzas que nunca podré pagar. Con razón dice de él uno de mis compañeros de generación, Sergio Pitol, en su admirable libro El arte de la fuga:

Debo a nuestro gran polígrafo y a los varios años de tenaz lectura la pasión por su lenguaje: admiro su secreta y serena originalidad [...] Era tal su discreción, que muchos aún ahora no acaban de enterarse de esa hazaña portentosa, la de transformar, renovándola, nuestra lengua (Fuentes, 2012, p. 69).

Las diversas variantes del modelo de los ensayos de Montaigne, sirven en el libro de Fuentes para responden a la pregunta que en la obra misma se plantea: « ¿cómo recuperar una incompleta y quizás ilusoria unidad perdida, al menos una semblanza de identidad recuperada? » (Fuentes, 2012, pp. 63 y 64). Es decir que, el libro nos descubre un escrito centrado en el tema de la identidad individual y colectiva, que además de abogar por un reconocimiento de otros, también argumenta por el reconocimiento de la propia identidad cultural de quien se expresa, como parte de un sujeto colectivo a quien también «defiende» y del que ofrece semblanza.

Otros estudiosos del ensayo, en su desarrollo posterior a su origen en la obra de Montaigne, han identificado algunas otras funciones que cumple el género y que tampoco pueden excluirse del escrito de Fuentes, un escrito que se ve afectado por esas modificaciones que han afectado al «modelo» primero. Belén Hernández, a quien antes hemos citado, ha enfatizado por ejemplo la función que el ensayo "moderno" cumple, o busca cumplir, como tipo particular de escrito: proporcionar al receptor, que requiere un estímulo intelectual y estético, dicho estímulo de un modo accesible. Es esa accesibilidad del ensayo la que determina para ella algunas de las características formales del mismo, 
pero también esas características formales, involucran, de acuerdo con sus palabras, una resistencia a la homogenización que se manifestaría en todo ensayo como «género transversal» que es:

La brevedad del discurso, la variedad de la temática, que se aproxima a argumentos científicos o antropológicos desde una crítica radical en la cual no están excluidas la sensibilidad y la intuición, mantienen la esperanza de que este género transversal resista los embates homogeneizadores de la globalización. (Cervera, Hernández y Adsuar, 2005, p. 8).

Lo que Belén Hernández denomina «embates homogenizadores de la globalización», correspondería, desde la perspectiva de Theodor W. Adorno (Adorno, 1962, pp. 11-36), a una implícita resistencia a la homogenización y normativa rigurosa propia de la llamada «retórica científica» positivista y neopositivista, que se manifiesta implícitamente en las características formales del ensayo, género que se distingue, precisamente, por no ajustarse rigurosamente a dicha retórica y mantenerse como un tipo de escrito flexible, próximo a lo artístico, lo que lo transforma -para Adorno- en objeto de desvaloraciones, causadas por la concepción de una antítesis manifiesta en: «el procedimiento de acotar el arte como reserva de irracionalidad, [e] identificar el conocimiento con la ciencia organizada» (Adorno 1962: 11). Punto observado también por Alfonso Rodríguez: «Adorno caracteriza al ensayo por oposición al tratado científico y a todo lo que rodea la ciencia positiva...» (Rodríguez, 2008, pp. 86 y 87). Sin embargo, el mismo filósofo alemán separa también el ensayo del arte, cuando señala: «... se acerca el ensayo a cierta independencia estética que es fácil reprocharle tomándola por mero préstamo del arte, del cual, empero, el ensayo se diferencia por su medio, los conceptos y por su aspiración a verdad...» (Adorno, 1962, p. 13). Estos deslindes planteados por Adorno han contribuido a que el ensayo sea repetidamente considerado como: «libre discurso reflexivo [...] discurso sintético de la pluralidad [...] unificada por la consideración crítica de la libre singularidad del sujeto» (Aullón De Haro, 1992, p. 130); «... género cuyos rasgos son la autonomía, la celebración de lo individual y el espíritu crítico» (Rodríguez, 2008, p. 84).

Estas consideraciones son también fundamentales para comprender algunas de las funciones que las propiedades discursivas del libro de Carlos Fuentes manifiestan al mezclar elementos de la semblanza, el testimonio y la autobiografía, con el ensayo y la ficción narrativa. Porque si en el ensayo literario y la ficción narrativa prevalecen demostraciones de competencias culturales e imaginativas, y el ensayo sirve a la reflexión crítica separándose del rigor de la retórica científica, sirve para la caracterización y celebración de una identidad determinada, en este caso individual y colectiva, los otros tipos textuales, uno apela a una demanda de reconocimiento y justicia moral, de corrección a otra «historia», que 
atañe al autor del libro, el otro al reconocimiento a un conjunto de intelectuales y personalidades públicas que han sido seleccionadas como integrantes de ese sujeto colectivo protagonista en este libro, a quienes se siente obligado difundir, con variados argumentos que descubren implícitamente también una necesidad de defensa dentro de determinado contexto caracterizado de modo muy específico y por contraste en el libro de Fuentes, con estas palabras: «el poder estaba en lo uno mismo decía, escribía o pensaba, no en lo que se decía, escribía o pensaba sobre uno» (Fuentes, 2012,p. 53).

De este modo, el análisis de las características tipológicas de géneros manifiesta la intencionalidad del sistema verbal, así como la función de los elementos pragmáticos en relación con las convenciones sociales que instauran el texto, dentro de los marcos de un circuito de comunicación concreto (como apuntaba acertadamente el escritor boliviano Renato Prada Oropeza). Puntos que no sólo resultan de interés para el analista de documentos históricos sino que, nos permiten conectar el análisis literario con la historia de las mentalidades, particularmente si consideramos que las demandas manifiestas en el libro se corresponden con los conflictos ideológicos que han caracterizado a algunos de los principales grupos de intelectuales en el contexto nacional, algunos de ellos abocados al desprestigio y desvaloración de ciertos intelectuales cuyas representaciones sociales están mediatizadas por intereses políticos y económicos muy específicos. Aspectos en los que sería largo detenernos, valga sólo señalar que tales conflictos se manifestarían, entre otras situaciones y casos concretos, en las oposiciones declaradas entre el denominado Grupo Vuelta, y su continuadora Letras Libres; y el Grupo Nexos. Conflictos que han sido objeto de estudio con diversos niveles de profundidad por variados analistas. ${ }^{13}$

A lo anterior se añade una percepción, por parte del escritor, de ese contexto social en el que se produce su obra como un contexto en el que existen circunstancias apremiantes, circunstancias de crisis y desestabilización, y en el que no se ha «hecho justicia» a los sujetos colectivos y al propio escritor que se expresa. Elementos que no sólo encuentran plena justificación cuando consideramos los niveles académicos de la población nacional expuestos a través de cifras sobre el número de libros que cada mexicano lee anualmente, los resultados de las estadísticas internacionales sobre educación básica y el lugar que México ocupa en las mismas, las características de las políticas culturales de las últimas décadas, los índices de violencia y el número de pobres en «pobreza extrema» del país, las modalidades específicas de inserción social y de vinculación con el poder político que han caracterizado a muchos intelectuales mexicanos «reconocidos» por su actividad cultural, la difusión y

\footnotetext{
13 Julio Patricio Eufracio Solano, Francisco Hinojosa, Ester Arroyo, Maarten van Delden, María Teresa Colchero Garrido, Avital H. Bloch, etc.
} 
el prestigio de que gozan las tendencias neoliberales sobre la educación, el desarrollo cultural y el quehacer académico. A lo que se añaden, por una parte, la reducción en el interés por la literatura y la cultura mexicana por parte de una Europa sumergida en sus propios problemas sociales, y por otra, la desvaloración y las «estrategias» de «anulación», olvido o francos ataques, dirigidos contra diversos intelectuales y artistas en el país, algunos de los cuales sólo fueron reconocidos en su propio contexto, luego de haber sido reconocidos por instancias legitimadoras externas.

Es indudable que en la obra de Fuentes se manifiestan también condicionantes individuales, circunstancias y apreciaciones personales muy concretas que afectaron al escritor; pero lo que a nosotros nos interesa destacar es la forma en que la realidad sociocultural específica que es el contexto de producción del libro, deja huellas determinantes en el escrito y hace visibles las contradicciones que caracterizan dicho contexto a través de los enunciados y rasgos formales de la obra.

\section{BIBLIOGRAFÍA}

Adorno, T.W. (1962). Notas de literatura. Barcelona: Ariel. Trad. Manuel Sacristán.

Aristóteles (2000) Retórica. Madrid: Gredos. Trad. Quintín Racionero.

Aullón de Haro, Pedro (1992). Teoría del ensayo. Madrid: Verbum.

Barthes, R. (1993). La aventura semiológica. Barcelona: Paidós. Trad. Ramón Alcalde.

Bedolla, D. (03 de abril de 2011). "La dominación adánica". En "Suplemento: La Jirafa. La cultura de cuello largo". Diario Regional de Zapotlán: [p. 1] Recuperado:

http://lajirafazapotlan.blogspot.mx/2011/04/la-dominacion-adanica.html;

Bensaïd, J. (1998). Avec le temps: carnets 1970-1998. Paris: Grasset.

Bensaïd, J. (2000). Soleils d'hiver: carnets 1998-2000. Paris : Grasset.

Bensaïd, J. (2002). Fuvres Autobiographiques. Paris: Grasset.

Beverley, J. (1987). Anatomía del testimonio, en Del Lazarillo al Sandinismo: Estudios sobre la función ideológica de la literatura española e hispanoamericana. Minneapolis Minnesota: The Prisma Institute.

Cervera, V., Hernández, B. y Adsuar, M. (2005). El ensayo como género literario. Murcia: Universidad de Murcia.

Carmen V. Vidaurre Zonas tipológicas intermedias......pp. 12 28 
Fuentes, C. (2012). Personas, México: Alfaguara.

Fuentes, C. (2009). Adán en Edén. México: Alfaguara.

Fuentes, C. (2008). La voluntad y la fortuna. México: Alfaguara.

Fuentes, C. (2003). La silla del águila. México: Alfaguara.

Fuentes, C. (1976). (a) Terra nostra. México: Joaquín Mortiz, $2^{a}$ ed.

Fuentes, C. (1976). (b) Cervantes o la crítica de la lectura. México: Joaquín Mortiz.

Fuentes, C. (1958). La región más transparente. México: Fondo de Cultura Económica.

Zunilda, G. (julio-diciembre 1981). "Semiótica, historia y ficción en Terra nostra". Revista Iberoamericana, 116-117 (47): 63-72.

Navarro Reyes, J. (2003). "Lo propio y lo ajeno. Génesis de los Ensayos de Montaigne". Cuadernos sobre Vico, 15-16: 271-290.

Navarro, S. (2002). Postmodernismo y metaficción historiográfica: una perspectiva interamericana. Valencia: Universitat de València.

Prada Oropeza, R. (2001). El discurso-testimonio y otros ensayos. México: UNAM.

Oviedo, J. (1982). Terra nostra: Sinfonía del Nuevo Mundo, en Escrito al Margen. Bogotá: Procultura: 143-175.

Reyes, A. (1985). Oración del 9 de febrero, en Alfonso Reyes. Obras Completas. Tomo XXIV. México: Fondo de Cultura Económica: 25-31.

Todorov, T. (1988). El origen de los géneros, en Teoría de los géneros literarios. Madrid: Arcos. Trad. Miguel ángel Garrido Gallardo.

Trias, S. (2003). Montaigne: la identidad como ensayo. Revista de Filosofía, 44 (21): 45-63

Vidaurre, C. (2004). Los signos del laberinto. Terra nostra de Carlos Fuentes. Guadalajara: Universidad de Guadalajara.

Vidaurre, C. (2012). Las continuidades ocultas. T. I. Madrid: LAP LAMBERT Academic Publishing $\mathrm{GmbH \&} \mathrm{Co.} \mathrm{KG.}$ 